\title{
Stereotactic reirradiation for local failure of brain metastases following previous radiosurgery: Systematic review and meta-analysis
}

\author{
Mauro Loi ${ }^{\mathrm{a}, *}$, Saverio Caini ${ }^{\mathrm{b}}$, Silvia Scoccianti ${ }^{\mathrm{a}}$, Pierluigi Bonomo ${ }^{\mathrm{a}}$, Kim De Vries $^{\mathrm{c}}$, \\ Giulio Francolini ${ }^{a}$, Gabriele Simontacchi ${ }^{a}$, Daniela Greto ${ }^{a}$, Isacco Desideri ${ }^{a}$, Icro Meattini ${ }^{a}$, \\ Joost Nuyttens ${ }^{c}$, Lorenzo Livi ${ }^{\mathrm{a}}$ \\ ${ }^{a}$ Radiotherapy Department, University of Florence, Florence, Italy \\ ${ }^{\mathrm{b}}$ Cancer Risk Factors and Lifestyle Epidemiology Unit, Institute for Cancer Research, Prevention and Clinical Network (ISPRO), Florence, Italy \\ ${ }^{\mathrm{c}}$ Department of Radiation Oncology, Erasmus MC Cancer Institute, Rotterdam, the Netherlands
}

\section{A R T I C L E I N F O}

\section{Keywords:}

Brain metastases

Stereotactic radiosurgery

Reirradiation

Repeat irradiation

Second stereotactic radiosurgery

In-field recurrence

Radionecrosis

\begin{abstract}
A B S T R A C T
Introduction: Local failure (LF) following stereotactic radiosurgery (SRS) of brain metastases (BM) may be treated with a second course of SRS (SRS2), though this procedure may increase the risk of symptomatic radionecrosis $(\mathrm{RN})$.

Methods: A literature search was conducted according to PRISMA to identify studies reporting LF, overall survival (OS) and RN rates following SRS2. Meta-analysis was performed to identify predictors of RN.

Results: Analysis included 11 studies (335 patients,389 metastases). Pooled 1-year LF was 24 \%(CI95 \% 19-30 $\%)$ : heterogeneity was acceptable ( $2=21.4 \%$ ). Median pooled OS was 14 months (Confidence Interval $95 \%$, CI95 \% 8.8-22.0 months). Cumulative crude RN rate was $13 \%$ (95 \%CI $8 \%-19 \%$ ), with acceptable heterogeneity $(\mathrm{I} 2=40.3 \%$ ). Subgroup analysis showed higher RN incidence in studies with median patient age $\geq 59$ years (13\% [95 \%CI $8 \%-19 \%$ ] vs $7 \%$ [95 \%CI $3 \%-12 \%$ ], $\mathrm{p}=0.004)$ and lower incidence following prior Whole Brain Radiotherapy (WBRT, $19 \%$ [95 \%CI $13 \%-25 \%$ ] vs 7\%[95 \%CI 3\%-13 \%], p = 0.004).

Conclusions: SRS2 is an effective strategy for in-site recurrence of BM previously treated with SRS.
\end{abstract}

\section{Introduction}

Approximately $20 \%$ of cancer patients will develop brain metastases (BM) during the clinical course of their disease, in particular melanoma, lung and breast cancer (Achrol et al., 2019). Most notably, this figure is expected to increase due to earlier BM detection and improved efficacy of systemic therapies, allowing for extended extra cranial disease control (Nieder et al., 2011). However, prognosis after occurrence of BM is still dismal, with an expected 2-years survival rate of $8.1 \%$ (Achrol et al., 2019).

Following results from recent clinical trials, stereotactic radiosurgery (SRS) has become a valuable option in patients with limited intracranial disease burden and a favorable life expectancy, with local control rates of approximately $70 \%$ at 1 year (Aoyama et al., 2006; Shaw et al., 2000; Rades et al., 2007) and a relatively benign toxicity profile in terms of neurocognitive impairment as compared to Whole Brain RadioTherapy (WBRT) (Chang et al., 2009). This comes at the price of a non-negligible risk of symptomatic radionecrosis (RN), an irreversible, radiation-induced, delayed brain injury that manifests in median 5 months (Stafinski et al., 2006) from treatment and is associated to progressive clinical deterioration and variable neurological impairment depending on the lesion location. This severe adverse event, occurring in up to $11 \%$ of cases at 24 months (Stafinski et al., 2006), has been correlated to multiple clinical and treatment-related features (Blonigen et al., 2010; Flickinger et al., 2000; Sneed et al., 2015; Stumpf et al., 2019; Kim et al., 2017; Miller et al., 2016). RN proves also challenging on a diagnostic point of view, since histological assessment is often difficult to obtain or misleading due to sampling errors related to possible coexistence of residual cancer cells and necrotic material in the biopsy (Narloch et al., 2017), while no single morphologic and/or metabolic imaging modality proved to be conclusive in differentiating RN from tumor recurrence (Vellayappan et al., 2018). Focusing on outcome, at present, no firm consensus has been established on the adequate treatment modality for patients experiencing local failure in BMs previously treated with SRS (Rae et al., 2016). Salvage options include chemotherapy, surgery, WBRT or supportive

\footnotetext{
* Corresponding author at: Radiotherapy Department, University of Florence, 3, Largo Brambilla, 50100, Florence, Italy.

E-mail address: mauro.loi@unifi.it (M. Loi).
} 
care: however, no clear evidence is available concerning the superiority of one modality over another, and no consensual recommendations have been formulated at present on this topic (Ammirati et al., 2010). Surgical resection may be considered as the preferred salvage modality, allowing for pathological assessment and providing, both in case of RN or tumor progression, removal of the causative process and prompt symptoms relief (Kano et al., 2009; Truong et al., 2006; Telera et al., 2013; Szeifert et al., 2006; Jagannathan et al., 2010; Vecil et al., 2005); however, it is unlikely that patients who were not initially eligible for surgical excision (a procedure that confers the highest local control rates in association to adjuvant SRS (Mahajan et al., 2017)), may receive surgery at the time of recurrence. WBRT, in consideration of neurocognitive impairment and disappointing results in terms of disease control, is usually deferred until onset of symptoms or proposed in case of multifocal relapse in patients with an uncontrolled primary tumor (McTyre et al., 2018). Concerning chemotherapy, significant heterogeneity exists with regard to tumor- (expected chemo-sensitivity) and drug-related variables, in particular blood-brain-barrier (BBB) penetration (Venur and Ahluwalia, 2016).

In the last 10 years, an increasing use of stereotactic reirradiation (SRS2) has been reported in the setting of recurrent brain metastases. However, this approach has been questioned both in terms of efficacy and tolerability. In the first instance, it is controversial whether a second course of radiotherapy might be effective following prior selection of purportedly radio-resistant clones (Kuwahara et al., 2018). Secondarily, and most notably, SRS2 might be correlated to an inacceptable risk of adverse events, resulting in a cumulative 1-year symptomatic RN incidence of $20 \%$ (Sneed et al., 2015).

We performed a systematic review and meta-analysis of the literature reporting outcomes and toxicity of patients receiving SRS2 for locally recurrent BMs following prior SRS.

\section{Material and methods}

\subsection{Selection criteria and search strategy}

A systematic review of the published literature was performed according to the PRISMA (Preferred Reporting Items for Systematic Reviews and Meta-Analyses) criteria. Due to lack of comparator in this setting, the PICO model was not applicable. Relevant articles were identified searching three electronic database (Pubmed, Scopus, Cochrane Library) by 4 authors (ML, DG, GF, KD) with use of the appropriate $\mathrm{MeSH}$ terms for the following search items: "brain", "encephalic", "cerebral" AND "stereotactic", "SRS", "radiosurgery" AND "reirradiation", "re irradiation", "salvage", "repeated", "repeat" AND "metastases", "metastatic", "metastasis", "in-field relapse", "in-field progression", "local relapse", "local failure".

Only fully published, peer-reviewed articles in English assessing the use of repeated stereotactic irradiation of brain metastases up to 1st November 2019 were included in our analysis. For the purpose of our study, case reports or in-silico case studies were not considered; papers analyzing use of SRS following exclusive WBRT or a second course of SRS for out-of-field progression were likewise excluded from analysis. In summary, only selected studies addressing patients who received two sequential SRS to the same brain metastasis due to intercurrent local failure were included in the final analysis. Duplicated studies or studies with insufficiently reported outcomes were removed. To verify the compliance to the predetermined search criteria, an evaluation was independently carried out by 2 author's teams (ML,GF,GS,PB; $\mathrm{KD}, \mathrm{DG}, \mathrm{ID}, \mathrm{SC}$ ); in case of inconsistency or disagreement between teams, a final decision was formulated with a third team (JN, LL, SS). The search methodology is summarized in Fig. 1.

\subsection{Validity assessment}

For each individual study, the risk of bias in each study was evaluated through the ROBINS-I (Sterne et al., 2016) tool to evaluate the following domains: a) bias due to confounding of effects; b) bias in selection of participants; c) bias due to classification of interventions; d) bias due to deviations from intended interventions; e) bias due to missing data; f) bias in measurement of the outcome; and g) bias in selection of the reported result.

\subsection{Data extraction and statistical analysis}

Data extraction from included articles was performed by one author team (ML,GF,GS,PB) and data accuracy was verified by a second team (KD,DG,ID,SC). Patients', disease and treatment-related features as well as local control rates and incidence of RN were collected and reported using descriptive statistics.

The study-specific median OS were pooled into a summary value and corresponding $95 \%$ confidence intervals (CI) by applying the "weighted median of medians" method (R statistical software, library metamedian; see McGrath et al. for reference (McGrath et al. (2019))). When not explicitly reported in the text, median OS was manually extracted from Kaplan-Meier survival curves (available for all remaining studies with the exception of one study). The study-specific proportion of patients experiencing a local failure at 6 and 12 months during follow-up, or radio necrosis at any time after SRS2, were pooled into summary proportions and corresponding $95 \% \mathrm{CI}$ using random-effects models implemented in the metaprop command in Stata (StataCorp, College Station, TX, USA, version 14) (Higgins and Thompson, 2002). The heterogeneity between studies was quantified using the $\mathrm{I}^{2}$ statistics, which can be interpreted as the proportion of variability across estimates that is due to actual heterogeneity rather than chance (Guan et al., 2019). Values of $\mathrm{I}^{2}$ above $50 \%$ are considered as denoting large heterogeneity: when this occurs, fitting meta-regression and subgroup analysis models (for continuous and categorical variables, respectively) is recommended in order to find study characteristics that correlate with the outcome and can therefore explain part of the heterogeneity. For the model focusing on the proportion of radionecrosis, some subgroup analyses where, however, conducted regardless of the value taken by the $\mathrm{I}^{2}$ statistics using the following variables that were suspected a priori to be possibly associated with the outcome: patient's age; biologically equivalent dose (BED) and irradiated volume of SRS2, and its delay from SRS1; and proportion of patients with prior whole brain irradiation (WBRT) or receiving SRS2 with a multi-fractionated schedule.

\section{Results}

Search workflow is outlined in Fig. 1. Thirty-two full-text papers were initially included out of 1136 potential references after check for duplicate or pertinence. Among them, 21 were excluded due to lack of prior SRS to the target metastasis (previous WBRT only, or first stereotactic irradiation of the target lesion after prior SRS to another intracranial site, or mixed interventions) or insufficient data reporting (Guan et al. (2019); Maranzano et al., 2019; Kim et al., 2018; Koiso et al., 2016; Huang et al., 2017; Shen et al., 2016; Bates et al., 2016; Yomo and Hayashi, 2016; Shultz et al., 2015; Monaco et al., 2014; Kurtz et al., 2014; Kim et al., 2013; Maranzano et al., 2012; Kwon et al., 2007a; Shuto et al., 2004; Hillard et al., 2003; Wowra et al., 2002; Bhatnagar et al., 2002; Noël et al., 2001; Davey et al., 1994; Kwon et al., 2007b). Hence, eleven studies were considered eligible for data extraction and included in the final meta-analysis (Iorio-Morin et al., 2019; Dincoglan et al., 2019; Moreau et al., 2018; Balermpas et al., 2018; Rana et al., 2017; McKay et al., 2017; Minniti et al., 2016; Greto et al., 2014; Terakedis et al., 2014; Holt et al., 2015; Koffer et al., 2020), accounting for 335 patients and 389 treated metastases. Median followup was available for 10/11 studies: for the pooled population, median follow-up was 12 (1-124) months. 


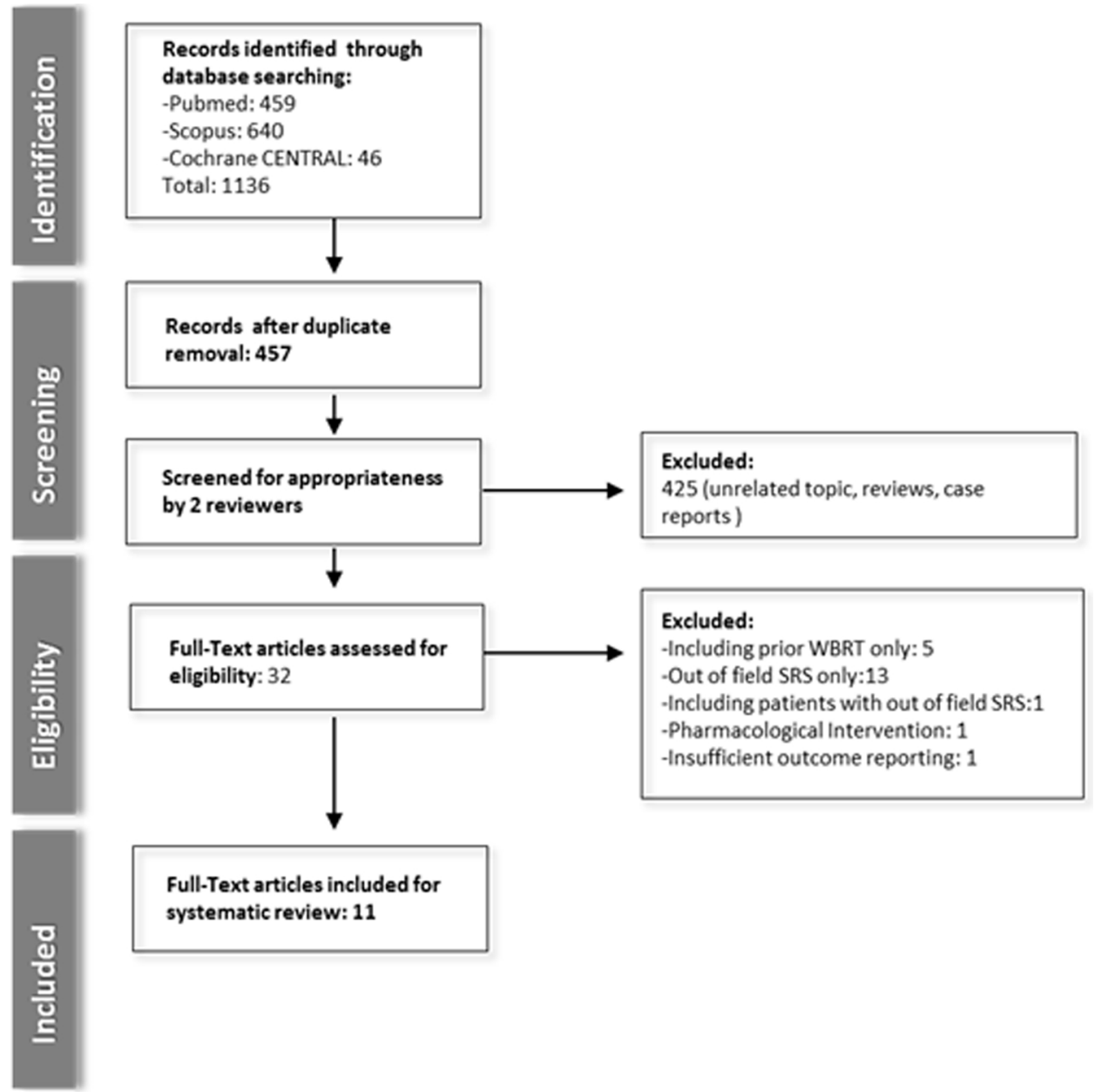

Fig. 1. Summary of the search methodology reported as a flow diagram.

\subsection{Validity of included studies}

The study design was retrospective in all cases. Risk of bias in individual studies is reported in Table 1. Risk of confounding bias was found low or unclear in all studies due to presence of possible uncontrolled confounders such as differences in primary tumor type and systemic treatments, prior administration of other local treatment, use of different dose regimens at first and second SRS, variability in age and performance status. Nevertheless, despite significant heterogeneity in the study population, risk level was not considered critical with regards to decision to treatment across the studies due to accurate reporting of clinical and treatment variables in most included papers.

Due to retrospective nature of all the studies, presence of significant selection bias cannot be excluded. However, prespecified use of consistent criteria for differential diagnosis between local failure and RN (both at the time of allocation to treatment and at response evaluation) within each study should be sufficient to minimize risk of selection bias in each cohort.

No major classification bias was highlighted due to clear definition of treatment procedures in all studies. Moreover, due to short duration of the proposed intervention (1-3 daily fractions), no major deviations from the planned treatment were reported in any study.

Risk of bias in measurement of the reported results was mostly low due to consistent use of validated methodology such as increased Relative Cerebral Blood Volume $>2$ (rCBV) at perfusion Magnetic Resonance Imaging (MRI) (Dincoglan et al., 2019; Minniti et al., 2016;

Table 1

Risk of bias summary: review authors' judgements about each risk of bias item for each included study. Low: $(+)$, moderate: $(++)$, unclear: (?).

\begin{tabular}{|c|c|c|c|c|c|c|c|}
\hline Study & Confounding & Selection & Classification & Deviation & Missing & Measurement & Reported \\
\hline Terakedis & (?) & $(+)$ & $(+)$ & $(+)$ & $(+)$ & $(+)$ & $(++)$ \\
\hline Greto & $(+)$ & $(+)$ & $(+)$ & $(+)$ & $(++)$ & $(+)$ & $(++)$ \\
\hline Minniti & $(+)$ & $(+)$ & $(+)$ & $(+)$ & $(+)$ & $(+)$ & $(++)$ \\
\hline McKay & (?) & $(+)$ & $(+)$ & $(+)$ & $(+)$ & $(+)$ & $(++)$ \\
\hline Rana & $(+)$ & $(+)$ & $(+)$ & $(+)$ & $(++)$ & $(+)$ & $(++)$ \\
\hline Balermpas & $(+)$ & $(+)$ & $(+)$ & $(+)$ & $(+)$ & $(+)$ & $(++)$ \\
\hline Moreau & $(+)$ & $(+)$ & $(+)$ & $(+)$ & $(++)$ & $(+)$ & $(++)$ \\
\hline Dincoglan & $(+)$ & $(+)$ & $(+)$ & $(+)$ & $(+)$ & $(+)$ & $(++)$ \\
\hline Holt & $(+)$ & (?) & $(+)$ & $(+)$ & $(+)$ & $(++)$ & $(++)$ \\
\hline Koffer & (?) & $(+)$ & $(+)$ & $(+)$ & $(+)$ & $(+)$ & $(++)$ \\
\hline Iorio-Morin & (?) & $(+)$ & $(+)$ & $(+)$ & $(+)$ & $(+)$ & $(++)$ \\
\hline
\end{tabular}


Koffer et al., 2020) and consensual diagnostic criteria such as RECIST (Rana et al., 2017; McKay et al., 2017; Greto et al., 2014; Terakedis et al., 2014; Holt et al., 2015), RANO-BM (Iorio-Morin et al., 2019; Moreau et al., 2018) and iRANO (Balermpas et al., 2018). However variability of criteria in use across the different studies is of concern, in particular with regard to the image modality of choice.

Risk of bias for missing data was found low in the majority of the examined papers due to enforcement of an adequate follow-up schedule with regard to the expected time to efficacy and toxicity event, with the exception of 2 studies due to short or unreported (Rana et al., 2017; Greto et al., 2014) duration of median follow-up. However, a general lack of analytic strategies for dealing with loss of information was found. The risk of selective report was considered moderate for all the studies due to lack of statistic strategies to account for competing events (death for extracranial progression), despite the use of a clearly defined estimate of the outcome and toxicity of the intervention. Overall, no critical bias risk was found in any study, though inter-study variability, in particular with regard to different modalities of outcome measurement, is of concern.

\subsection{Clinical and treatment-related characteristics}

Clinical and treatment related characteristics for all studies are summarized in Tables 2 and 3, respectively. Median age, reported in all studies, was 59 years (range 27-88). Karnofsky Performance Status (KPS) was present in 8/11 studies, showing a KPS $>70 \%$ in $117 / 214$ (55\%) patients. Information concerning primary tumor were found in all studies, though only 8/11 studies reported this data on a per-patient basis. Hence, out of 288 assessable patients, lung cancer (101/288, 35 $\%)$, melanoma (70/288, $24 \%)$ and breast $(62 / 288,22 \%)$ cancer were the most represented histology. Pathological assessment was performed only in 34 out of 153 metastases from 5/11 studies. In the remaining cases, diagnosis of recurrence was based on contrast-enhanced (CE) MRI, perfusion MRI, perfusion MRI plus spectroscopy and perfusion MRI plus DOTA-PET CT in respectively 6, 2, 2, and 1 studies. Surgical excision at any time point before SRS2 was acknowledged in $8 / 11$ studies, and was performed in 89/249 (36 \%) patients: in all cases, however, residual disease was present at the time of SRS2. Information on WBRT was available in all studies: WBRT was delivered at any time point before SRS2 in approximately one third of cases (102/335, 30\%). Median dose delivered at the time of first SRS (SRS1) was reported in 8/ 11 studies, corresponding to a median prescription dose of 20 (18-24) Gy in 1 fraction. Time interval between SRS1 and SRS2 was reported in all the studies, corresponding to a median 13 (6-19) months delay.

Median tumor volume at reirradiation was 12 (1-40) cc. Median dose delivered at the time of SRS2 was 19 (15.5-26.5) Gy in 1 (1-3) fraction, translating into an extrapolated median Biological Effective Dose (BED) of 50.4 Gy assuming an $\alpha / \beta=10$. Treatment was delivered using a single-fraction and a multifractionated regimen in respectively $72 \%(280 / 389)$ and $28 \%(109 / 389)$ patients.

\subsection{Local control and overall survival}

In the pooled population from eleven studies, 6-months and 1-year local failure estimates were $7 \%$ (CI95 \% 4-12\%) and $24 \%$ (CI95 \% $19-30 \%)$. Acceptable heterogeneity was found in both cases $\left(\mathrm{I}^{2}=35.3\right.$ $\%$ and $21.4 \%$, respectively) (Fig. 2 A). Five studies reported on predictive factors correlated to increased local failure risk, including primary tumor type (melanoma versus other histotypes), lack of prior WBRT, tumor size at SRS2, prescription dose at SRS2, initial best response at first SRS, KPS, and controlled extracranial disease (see Table 4).

Pooled estimate of median survival was obtained from 9 studies, resulting in a median pooled OS of 14 months (CI95 \% 8.8-22.0 months). Among the predictive factors, only lower prescription dose at SRS2 was found significantly associated with poorer survival in one

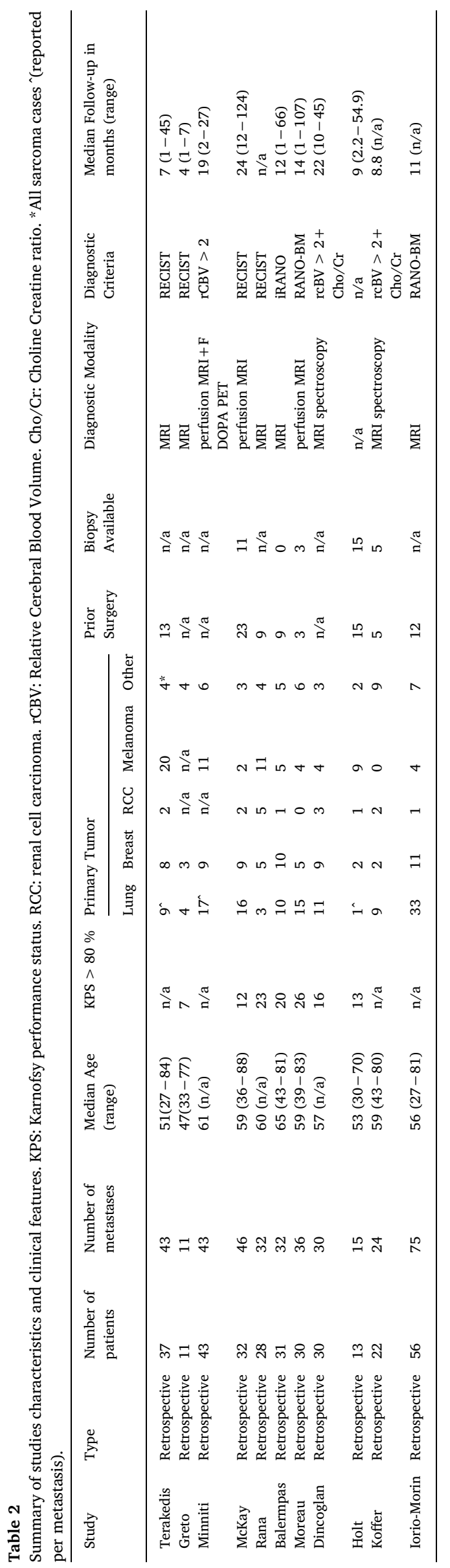


Table 3

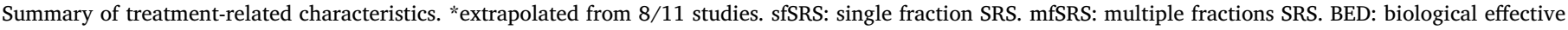
dose.

\begin{tabular}{|c|c|c|c|c|c|c|c|c|c|c|c|c|}
\hline Study & $\begin{array}{l}\text { Number of } \\
\text { patients }\end{array}$ & $\begin{array}{l}\text { Number of } \\
\text { metastases }\end{array}$ & WBRT & $\begin{array}{l}\text { Median } \\
\text { SRS1 dose } \\
\text { (in Gy) }\end{array}$ & $\begin{array}{l}\text { Median } \\
\text { delay SRS1 } \\
\text { to SRS2 dose } \\
\text { (in months) }\end{array}$ & $\begin{array}{l}\text { Median } \\
\text { SRS2 dose } \\
\text { (in Gy) }\end{array}$ & $\begin{array}{l}\text { Median } \\
\text { SRS2 } n^{\circ} \text { of } \\
\text { fractions }\end{array}$ & $\begin{array}{l}\text { Number of } \\
\text { metastases } \\
\text { receiving } \\
\text { sfSRS }\end{array}$ & $\begin{array}{l}\text { Number of } \\
\text { metastases } \\
\text { receiving } \\
\text { mfSRS }\end{array}$ & $\begin{array}{l}\% \text { of } \\
\text { multiple } \\
\text { fractions } \\
\text { SRS2 }\end{array}$ & $\begin{array}{l}\text { Median } \\
\text { SRS2 BED } \\
\text { (in Gy) }\end{array}$ & $\begin{array}{l}\text { Tumor } \\
\text { size at } \\
\text { SRS2 (cc) }\end{array}$ \\
\hline Terakedis & 43 & 43 & 17 & 18 & 9 & 18 & 1 & 43 & 0 & 0 & 50,4 & 2,2 \\
\hline Greto & 13 & 13 & 6 & $\mathrm{n} / \mathrm{a}$ & 13 & 19 & 1 & 9 & 4 & 36 & 53,5 & 40,0 \\
\hline Minniti & 43 & 43 & 0 & $\mathrm{n} / \mathrm{a}$ & 17 & 21 & 3 & 0 & 43 & 100 & 35,7 & 12,0 \\
\hline McKay & 46 & 46 & 8 & 20 & 19 & 20 & 1 & 46 & 0 & 0 & 60 & 1,0 \\
\hline Rana & 32 & 32 & 8 & 24 & 10 & 26.5 & 3 & 19 & 13 & 40 & 65,1 & 1,35 \\
\hline Balermpas & 32 & 32 & 4 & 18 & 12 & 19 & 1 & 24 & 8 & 25 & 50,4 & 2,5 \\
\hline Moreau & 36 & 36 & 24 & $\mathrm{n} / \mathrm{a}$ & 15 & 18 & 1 & 36 & 0 & 0 & 50,4 & 4,8 \\
\hline Dincoglan & 30 & 30 & 0 & 18 & 14 & 21 & 3 & 0 & 30 & 100 & 35,7 & 14,0 \\
\hline Holt & 15 & 15 & 1 & 21 & 6,4 & 21 & 3 & 6 & 9 & 60 & 35,7 & 9,8 \\
\hline Koffer & 24 & 24 & 8 & 18 & 13 & 15,5 & 1 & 24 & 0 & 0 & 33 & 3,3 \\
\hline Iorio-Morin & 75 & 75 & 26 & 20 & 13 & 18 & 1 & 75 & 0 & 0 & 50,4 & 1,19 \\
\hline Summary & 335 & 389 & 102 & $20 *$ & 13 & 19 & 1 & 282 & 107 & 28 & 50,4 & 3,30 \\
\hline
\end{tabular}

study.

\subsection{Radionecrosis}

Cumulative $\mathrm{RN}$ rate was calculated from eleven studies, resulting in a crude median value of $13 \%$ (95 \%CI $8 \%-19 \%$ ) in the pooled population at the end of the follow-up period, with a moderate, yet acceptable heterogeneity $\left(\mathrm{I}^{2}=40.3 \%\right.$ ) (Fig. $2 \mathrm{~B}$ ). Since no study reported neither mean nor total follow-up, pooled estimate of the incidence was not assessable. Median time from SRS2 to RN was reported in 4 studies, ranging from 3 to 8 months (median 4 months). Risk factors for $\mathrm{RN}$ are reported in Table 4. A trend for increased risk in case of prior WBRT was observed in one study, though not reaching statistical significance $(\mathrm{p}=0.05)$. A meta-regression for variables uniformly reported across the pooled population (see Table 3 ) was not contributive due to insufficient number of included studies. Therefore, a subgroup analysis was carried out to compare median values and the correspondent percentage of RN: a significantly higher incidence of RN was found in studies with median age $\geq 59$ years $(n=6,13 \%$ [95 \%CI $8 \%-19 \%$ ] vs 7\% [95 \%CI $3 \%-12 \%$ ], $\mathrm{p}=0.004$ ) and prior use of WBRT in $\leq 29 \%$ of the study population $(\mathrm{n}=6,19 \%$ [95 \%CI $13 \%-25 \%$ ] vs $7 \%$ [95 $\%$ CI $3 \%-13 \%], p=0.004)$. No significant differences in terms of RN among studies was found with regard to median prescribed BED, tumor volume and use of a multifractionated schedule at SRS2. Median interval from SRS1 to SRS2, albeit yielding a moderate difference between $\mathrm{RN}$ rates for studies reporting a delay superior $(\mathrm{n}=4,18 \%$ [95
$\%$ CI $10 \%-2 \%]$ ) versus equal or inferior to 13 months ( $=7,10 \%$ [95 $\%$ CI $5 \%-16 \%]$ ), did note prove significant at statistical analysis $(\mathrm{p}=0.148$, NS).

\section{Discussion}

Limited data are available concerning the optimal salvage modality following in-site recurrence of brain metastases after upfront SRS. Treatment options include surgical excision, chemotherapy or reirradiation by WBRT or SRS2. Decision is often based on patient's age and functional status, extracranial disease control, intracranial tumor burden, previous treatment and type of primary cancer (Ammirati et al., 2010). Whenever feasible, surgical excision is the preferred option, allowing for discrimination between tumor recurrence and $\mathrm{RN}$ and resulting in satisfactory local control rates ranging from $62 \%-93 \%$ at 1 year (Kano et al., 2009; Truong et al., 2006; Vecil et al., 2005) and a median survival of 8.7 months after surgery (Truong et al., 2006). However, its use is currently restricted to selected cases, accounting for $1-11 \%$ of patients eligible for salvage treatment of recurrent BM (Rae et al., 2016; Szeifert et al., 2006), in consideration of its invasive character that may be related to a non-negligible mortality and morbidity risk (Kano et al., 2009). Despite introduction of less invasive modalities such as laser-interstitial thermal therapy (LITT), a neurosurgical approach does not obviate for subsequent use of reirradiation to confer additional local control benefit in most cases (Hong et al., 2019).

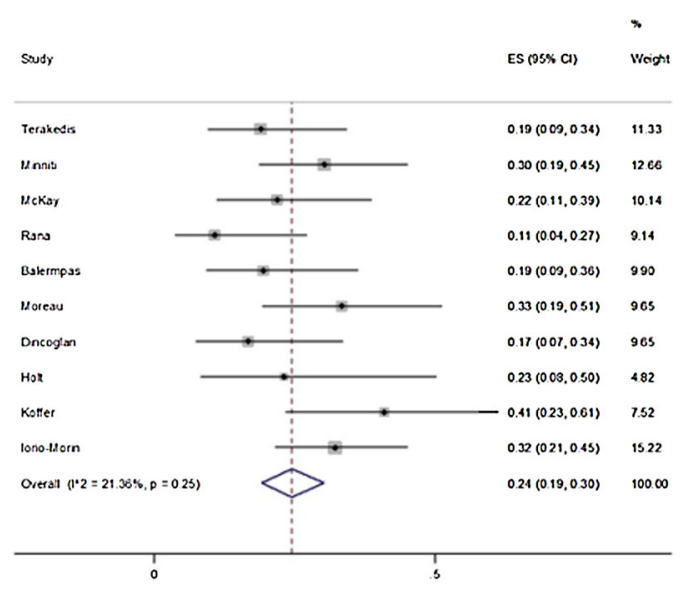

A

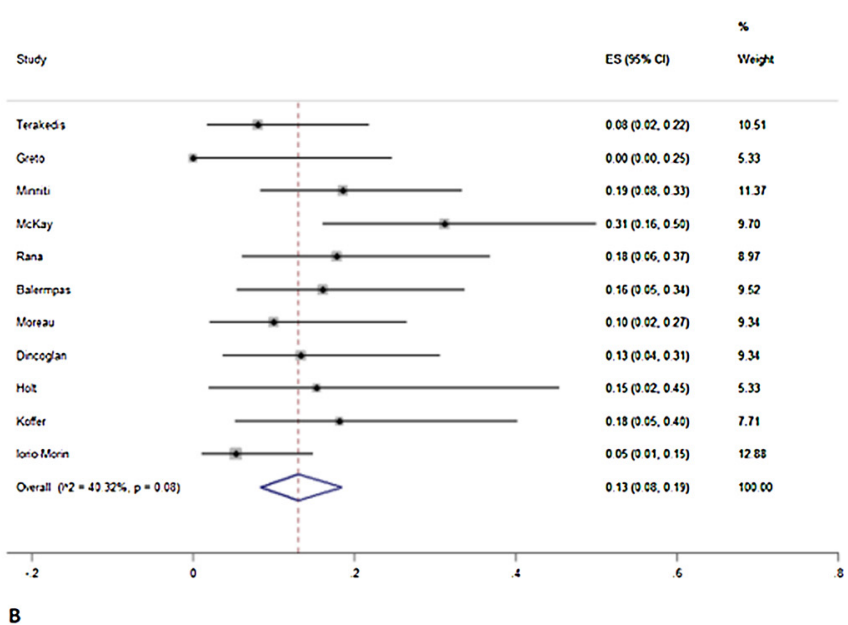

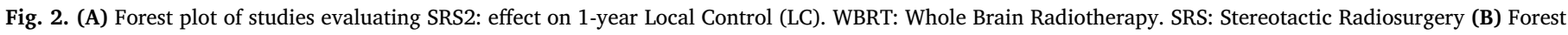
plot of studies evaluating SRS2: effect on Radionecrosis (RN) crude incidence. ES: Effect Size. 

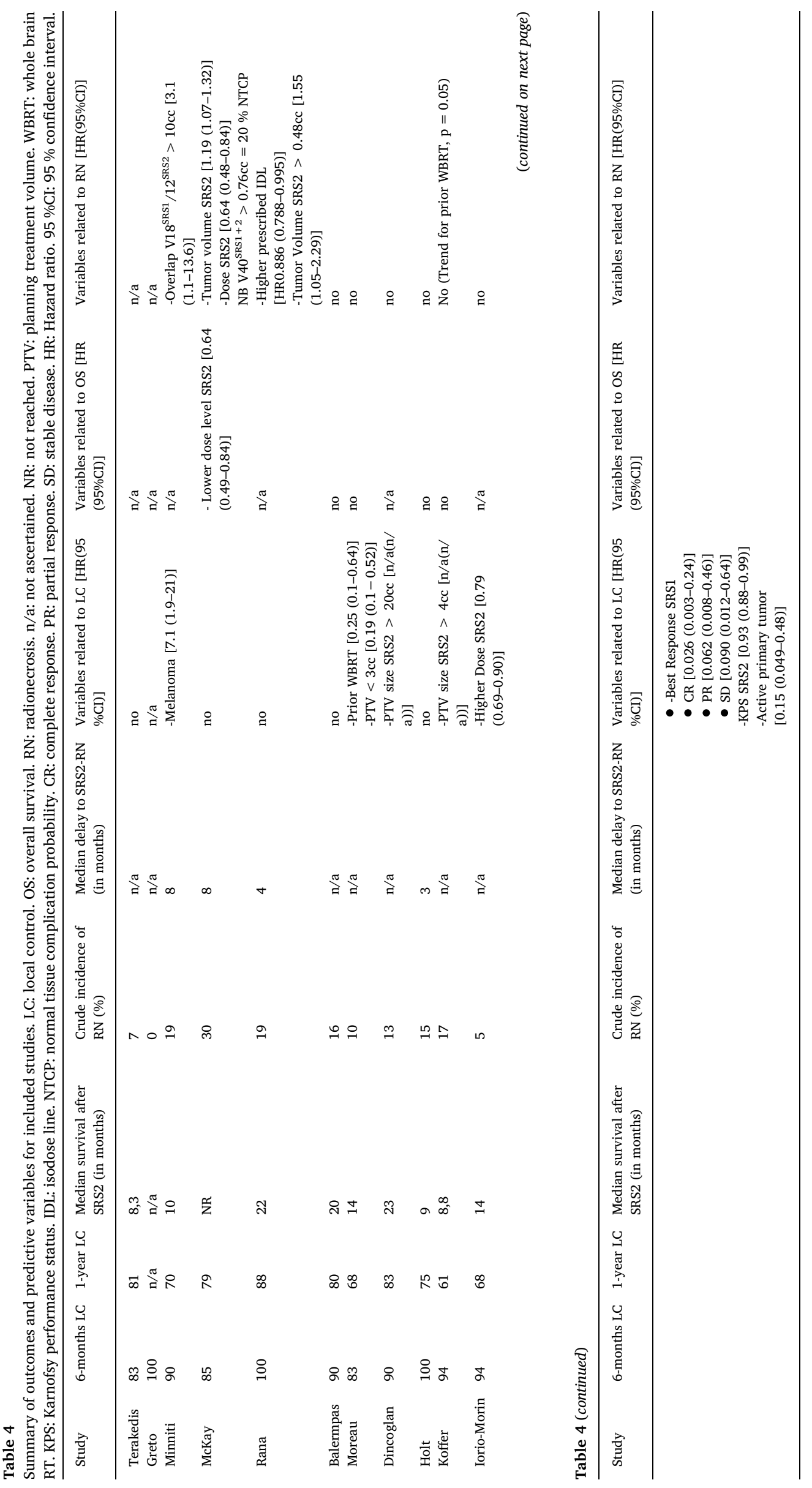
In our meta-analysis, we addressed the use of a second course of SRS to recurrent BM. Eleven retrospective studies were included, accounting for 335 patients and 389 treated metastases. Validity assessment using the ROBINS-I tool was carried out, showing no critical bias risk in each domain for all the included articles. The most prominent finding in our study is the pooled $24 \% 1$-year local failure rate, suggesting that local control rates following SRS2 do not dramatically differ from those reported by prospective trials of upfront SRS (Aoyama et al., 2006; Shaw et al., 2000; Stafinski et al., 2006). Most interestingly, median survival in the pooled population was 14 months from the date of SRS2. This is similar to median survival following a first course of SRS in selected subsets, that is approximately 11 months in patients with high score at GPA prognostic index (Sperduto et al., 2012).

These figures are comparable with outcomes from surgical series (LC rate of 62\%-93 \% at 1 year (Kano et al., 2009; Truong et al., 2006; Vecil et al., 2005) and median survival of 8.7 months after surgery (Truong et al., 2006)). However, direct comparison between SRS2 and resection is hindered by frequent combined reporting of surgical excision both as salvage therapy for in-field progression of BM and as a palliation for symptomatic RN to decrease neurologic impairment and steroid dependency (Jagannathan et al., 2010). Interestingly, local failure and median survival in the pooled population showed low interstudies heterogeneity, with $\mathrm{I}^{2}<50 \%$ for both endpoints.

Another major finding in our work is the pooled rate of $\mathrm{RN}$, estimated at $13 \%$ at a median follow up of 12 months. Our finding is in line with previous reports, that highlighted an increased risk of RN following SRS2 of brain metastases (Sneed et al., 2015; Minniti et al., 2016). However, it should be pointed out that incidence of $\mathrm{RN}$ is variable among different salvage modalities for recurrent BM following SRS. Rae et al. (Rae et al., 2016) reported the risk of RN using different salvage strategies in patients with recurrent BM after SRS, excluding SRS2: despite no significant increase in incidence of RN in patients receiving salvage therapy, a baseline risk of $\mathrm{RN}$ was found in $4.5 \%$ of salvaged patients (all intervention confounded), that rose to $21 \%$ in patients receiving concurrent SRS to a distant site and WBRT.

Three studies (see Table 4) reported predictive factors correlated to increased risk of RN, consisting of tumor volume at SRS2, higher prescribed dose at SRS2 and larger overlap area between first SRS and SRS2 volumes in 2, 2 and 1 studies, respectively. In the subset analysis carried out on the pooled population, only younger age and prior use of WBRT were associated to lower RN incidence.

While older age is not a contraindication to SRS, as demonstrated by previous experiences (Minniti et al., 2013), the correlation between age and radiation-related brain damage has long been known: the severity of white-matter alterations have been found to increase with advancing age, as a possible consequence of age-related underlying vascular and neurological injury though important inter-individual variability is also observed (Tsuruda et al., 1987). Comprehensive geriatric assessment, including evaluation of functional status and comorbidities is strongly recommended (Frasca et al., 2018).

Focusing on WBRT, a possible protective role may seem counterintuitive, but $\mathrm{RN}$ is a complex phenomenon in which inflammatory cells, perivascular lymphocytes, GFAP-positive astrocytes and cytokine secretion play a key role in chronic inflammatory response (Yoshii, 2008). It could be hypothesized that previous WBRT may contribute to decreased activity of all elements cooperating in late tissue response to radiotherapy, delivering lower dose to the whole brain parenchyma and providing an unfavorable microenvironment to inflammation: thus, SRS2 may act on a "cold" brain parenchyma, unable to arrange a response to radiation damage. More probably, it could be a confirmation that previous WBRT had inconclusive association with risk of $\mathrm{RN}$, as shown in several series regarding SRS1 that reported conflicting results (Sneed et al., 2015; Schüttrumpf et al., 2014; Kohutek et al., 2015; Donovan et al., 2019), in particular with regard to variable timing of the procedure and its place in the treatment sequence.

Interestingly, in our analysis, use of fractionated schedules was not found protective with regard to occurrence of $\mathrm{RN}$, as this strategy is frequently used to mitigate toxicity in presence of large tumors that have an intrinsically higher risk of RN (Donovan et al., 2019): for this reason, no definitive conclusion can be drawn about threshold volume and optimal radiation schedule in patients who are candidate to SRS2. It is also noteworthy that interval between the SRS courses did not significantly influence the onset of RN.

The main limitations of our work refer mainly to the retrospective nature and the small number of eligible studies identified according to our search criteria. Moreover, despite use of validated parameters for the differential diagnosis between progression versus $\mathrm{RN}$ and definition of response following SRS2, a lack of standardized definition for these events across different series represents a potential source of bias and should be addressed by consensual use of objective criteria such as the RANO-BM (Lin et al., 2015). Due to heterogeneity and inconsistent reporting of primary tumor type and concurrent medications, a possible impact of tumor histology and systemic therapy (with particular focus to molecular-targeted agents) could not be ruled out in our analysis. For these reason, no clear indications can be drawn on patient selection, in particular with regard to the risk of developing RN after SRS2.

\section{Conclusion}

In patients experiencing in-site recurrence of BM following upfront SRS, a second course of SRS (SRS2) is an effective strategy. According to our meta-analysis SRS results in median overall survival superior to 12 months, while local control rates compares favorably with results from surgical series. However, SRS2 is associated, in $13 \%$ of pooled patients, to development of symptomatic $\mathrm{RN}$, a severe adverse event causing significant psychophysical impairment. Unfortunately, available data did not allow a robust meta-analysis of predictive factors. Although younger age and previous use of WBRT were found protective with regard to RN occurrence at subset analysis, no impact was demonstrated for tumor volume, use of multifractionated schedules, higher biological effective dose and longer time interval from first SRS. Consensual assessment of response using consensual criteria should be of primary concern in future studies.

\section{CRediT authorship contribution statement}

Mauro Loi: Conceptualization, Data curation, Investigation, Methodology, Writing - original draft. Saverio Caini: Data curation, Formal analysis, Investigation, Methodology, Software, Writing - original draft. Silvia Scoccianti: Investigation, Methodology, Validation, Visualization, Writing - review \& editing. Pierluigi Bonomo: Investigation, Data curation, Writing - original draft. Kim De Vries: Investigation, Data curation, Writing - original draft. Giulio Francolini: Investigation, Data curation, Writing - original draft. Gabriele Simontacchi: Investigation, Methodology, Validation, Visualization, Writing - review \& editing. Daniela Greto: Investigation, Data curation, Writing - original draft. Isacco Desideri: Investigation, Data curation, Writing - original draft. Icro Meattini: Writing - review \& editing. Joost Nuyttens: Supervision, Investigation, Methodology, Validation, Visualization, Writing - review \& editing. Lorenzo Livi: Investigation, Methodology, Validation, Visualization, Writing - review \& editing.

\section{Declaration of Competing Interest}

The authors have no conflict of interests to declare

\section{References}

Achrol, A.S., Rennert, R.C., Anders, C., Soffietti, R., Ahluwalia, M.S., Nayak, L., Peters, S., Arvold, N.D., Harsh, G.R., Steeg, P.S., Chang, S.D., 2019. Brain metastases. Nat. Rev. Dis. Primers 5, 5. https://doi.org/10.1038/s41572-018-0055-y. Review. PubMed 
PMID: 30655533

Ammirati, M., Cobbs, C.S., Linskey, M.E., Paleologos, N.A., Ryken, T.C., Burri, S.H., Asher, A.L., Loeffler, J.S., Robinson, P.D., Andrews, D.W., Gaspar, L.E., Kondziolka, D., McDermott, M., Mehta, M.P., Mikkelsen, T., Olson, J.J., Patchell, R.A., Kalkanis, S.N., 2010. The role of retreatment in the management of recurrent/progressive brain metastases: a systematic review and evidence-based clinical practice guideline. J. Neurooncol. 96, 85-96. https://doi.org/10.1007/s11060-009-0055-6.PubMed. PMID: 19957016;PubMed Central PMCID: PMC2808530.

Aoyama, H., Shirato, H., Tago, M., Nakagawa, K., Toyoda, T., Hatano, K., Kenjyo, M., Oya, N., Hirota, S., Shioura, H., Kunieda, E., Inomata, T., Hayakawa, K., Katoh, N., Kobashi, G., 2006. Stereotactic radiosurgery plus whole-brain radiation therapy vs stereotactic radiosurgery alone for treatment of brain metastases: a randomized controlled trial. JAMA 295, 2483-2491 PubMed PMID: 16757720.

Balermpas, P., Stera, S., Müller von der Grün, J., Loutfi-Krauss, B., Forster, Mt, Wagner, M., Keller, C., Rödel, C., Seifert, V., Blanck, O., Wolff, R., 2018. Repeated in-field radiosurgery for locally recurrent brain metastases: feasibility, results and survival in a heavily treated patient cohort. PLoS One 13, e0198692. https://doi.org/10.1371/ journal.pone.0198692. PubMed PMID: 29874299; PubMed Central PMCID: PMC5991396.

Bates, J.E., Youn, P., Usuki, K.Y., Dhakal, S., Milano, M.T., 2016. Repeat courses of SRS in patients initially treated with SRS alone for brain-metastatic melanoma. Melanoma Manag. 3, 97-104. https://doi.org/10.2217/mmt-2016-0005. PubMed PMID: 30190878; PubMed Central PMCID: PMC6094646.

Bhatnagar, A., Heron, D.E., Kondziolka, D., Lunsford, L.D., Flickinger, J.C., 2002. Analysis of repeat stereotactic radiosurgery for progressive primary and metastatic CNS tumors. Int. J. Radiat. Oncol. Biol. Phys. 53 (3), 527-532 PubMed PMID:12062593.

Blonigen, B.J., Steinmetz, R.D., Levin, L., Lamba, M.A., Warnick, R.E., Breneman, J.C., 2010. Irradiated volume as a predictor of brain radionecrosis after linear accelerator stereotactic radiosurgery. Int. J. Radiat. Oncol. Biol. Phys. 77, 996-1001. https://doi. org/10.1016/j.ijrobp.2009.06.006. PubMed PMID: 19783374.

Chang, E.L., Wefel, J.S., Hess, K.R., Allen, P.K., Lang, F.F., Kornguth, D.G., Arbuckle, R.B., Swint, J.M., Shiu, A.S., Maor, M.H., Meyers, C.A., 2009. Neurocognition in patients with brain metastases treated with radiosurgery or radiosurgery plus whole-brainirradiation: a randomised controlled trial. Lancet Oncol. 10, 1037-1044. https:// doi.org/10.1016/S1470-2045(09)70263-3. PubMed PMID: 19801201.

Davey, P., O'Brien, P.F., Schwartz, M.L., Cooper, P.W., 1994. A phase I/II study of salvage radiosurgery in the treatment of recurrent brain metastases. Br. J. Neurosurg. 8, 717-723 PubMed PMID: 7718169.

Dincoglan, F., Sager, O., Demiral, S., Gamsiz, H., Uysal, B., Onal, E., Ekmen, A., Dirican, B., Beyzadeoglu, M., 2019. Fractionated stereotactic radiosurgery for locally recurrent brain metastases after failed stereotactic radiosurgery. Indian J. Cancer 56, 151-156. https://doi.org/10.4103/ijc.IJC_786_18. PubMed PMID: 31062735.

Donovan, E.K., Parpia, S., Greenspoon, J.N., 2019. Incidence of radionecrosis in singlefraction radiosurgery compared with fractionated radiotherapy in the treatment of brain metastasis. Curr. Oncol. 26, e328-e333. https://doi.org/10.3747/co.26.4749. PubMed PMID: 31285676; PubMed Central PMCID: PMC6588068.

Flickinger, J.C., Kondziolka, D., Lunsford, L.D., Kassam, A., Phuong, L.K., Liscak, R., Pollock, B., 2000. Development of a model to predict permanent symptomatic postradiosurgery injury for arteriovenous malformation patients. Arteriovenous Malformation Radiosurgery Study Group. Int. J. Radiat. Oncol. Biol. Phys. 46, 1143-1148 PubMed PMID: 10725624.

Frasca, M., Soubeyran, P., Bellera, C., Rainfray, M., Leffondre, K., 2018. MathoulinPélissier S; oncodage group. Alterations in comprehensive geriatric assessment decrease survival of elderly patients with cancer. Eur. J. Cancer 90, 10-18. https://doi. org /10.1016/j.ejca.2017.11.013. PubMed PMID: 29268140.

Greto, D., Livi, L., Bonomo, P., Masi, L., Detti, B., Meattini, I., Mangoni, M., Doro, R., Favuzza, V., Cipressi, S., Iermano, C., Bonucci, I., Loi, M., Biti, G., 2014. Cyberknife stereotactic radiosurgery for the re-irradiation of brain lesions: a single-centre experience. Radiol. Med. 119, 721-726. https://doi.org/10.1007/s11547-014-0383-2. PubMed PMID: 24469988.

Guan, Y., Wang, C., Zhu, H., Li, J., Xu, W., Sun, L., Pan, L., Dai, J., Wang, Y., Wang, E., Wang, X., 2019. Hypofractionated radiosurgery plus bevacizumab for locally recurrent brain metastasis with previously high-dose irradiation. World Neurosurg. (September), 7 pii: S1878-8750(19)32400-3. doi: 10.1016/j.wneu.2019.08.233. PubMed PMID: 31505283.

Higgins, J.P., Thompson, S.G., 2002. Quantifying heterogeneity in a meta-analysis. Stat. Med. 21, 1539-1558 PubMed PMID: 12111919.

Hillard, V.H., Shih, L.L., Chin, S., Moorthy, C.R., Benzil, D.L., 2003. Safety of multiple stereotactic radiosurgery treatments for multiple brain lesions. J. Neurooncol. 63, 271-278 PubMed PMID: 12892233.

Holt, D.E., Gill, B.S., Clump, D.A., Leeman, J.E., Burton, S.A., Amankulor, N.M., Engh, J.A., Heron, D.E., 2015. Tumor bed radiosurgery following resection and prior stereotactic radiosurgery for locally persistent brain metastasis. Front. Oncol. 5, 84. https://doi.org/10.3389/fonc.2015.00084. PubMed PMID: 25905042; PubMed Central PMCID: PMC4389371

Hong, C.S., Deng, D., Vera, A., Chiang, V.L., 2019. Laser-interstitial thermal therapy compared to craniotomy for treatment of radiation necrosis or recurrent tumor in brain metastases failing radiosurgery. J. Neurooncol. 142 (2), 309-317. https://doi. org/10.1007/s11060-019-03097-z. PubMed PMID: 30656529.

Huang, Z., Sun, B., Shen, G., Cha, L., Meng, X., Wang, J., Zhou, Z., Wu, S., 2017. Brain metastasis reirradiation in patients with advanced breast cancer. J. Radiat. Res. 58 142-148. https://doi.org/10.1093/jrr/rrw087. PubMed PMID: 27707842; PubMed Central PMCID: PMC5321192.

Iorio-Morin, C., Mercure-Cyr, R., Figueiredo, G., Touchette, C.J., Masson-Côté, L., Mathieu, D., 2019. Repeat stereotactic radiosurgery for the management of locally recurrent brain metastases. J. Neurooncol. 145, 551-559. https://doi.org/10.1007/ s11060-019-03323-8. PubMed PMID: 31667732.

Jagannathan, J., Bourne, T.D., Schlesinger, D., Yen, C.P., Shaffrey, M.E., Laws Jr, E.R. Sheehan, J.P., 2010. Clinical and pathological characteristics of brain metastasis resected after failed radiosurgery. Neurosurgery 66, 208-217. https://doi.org/10. 1227/01.NEU.0000359318.90478.69. PubMed PMID: 20023552.

Kano, H., Kondziolka, D., Zorro, O., Lobato-Polo, J., Flickinger, J.C., Lunsford, L.D., 2009. The results of resection after stereotactic radiosurgery for brain metastases. J. Neurosurg. 111, 825-831. https://doi.org/10.3171/2009.4.JNS09246. PubMed PMID: 19425892.

Kim, D.H., Schultheiss, T.E., Radany, E.H., Badie, B., Pezner, R.D., 2013. Clinical outcomes of patients treated with a second course of stereotactic radiosurgery for locally or regionally recurrent brain metastases after prior stereotactic radiosurgery. J. Neurooncol. 115, 37-43. https://doi.org/10.1007/s11060-013-1191-6. PubMed PMID: 23813230.

Kim, J.M., Miller, J.A., Kotecha, R., Xiao, R., Juloori, A., Ward, M.C., Ahluwalia, M.S. Mohammadi, A.M., Peereboom, D.M., Murphy, E.S., Suh, J.H., Barnett, G.H., Vogelbaum, M.A., Angelov, L., Stevens, G.H., Chao, S.T., 2017. The risk of radiation necrosis following stereotactic radiosurgery with concurrent systemic therapies. J. Neurooncol. 133, 357-368. https://doi.org/10.1007/s11060-017-2442-8. PubMed PMID: 28434110.

Kim, I.Y., Jung, S., Jung, T.Y., Moon, K.S., Jang, W.Y., Park, J.Y., Song, T.W., Lim, S.H., 2018. Repeat stereotactic radiosurgery for recurred metastatic brain tumors. J. Korean Neurosurg. Soc. 61, 633-639. https://doi.org/10.3340/jkns.2017.0238. PubMed PMID: 30064202; PubMed Central PMCID: PMC6129758.

Koffer, P., Chan, J., Rava, P., Gorovets, D., Ebner, D., Savir, G., Kinsella, T., Cielo, D., Hepel, J.T., 2020. Repeat stereotactic radiosurgery for locally recurrent brain metastases. World Neurosurg. 104, 589-593. https://doi.org/10.1016/j.wneu.2017.04. 103. PubMed PMID: 28450235.

Kohutek, Z.A., Yamada, Y., Chan, T.A., Brennan, C.W., Tabar, V., Gutin, P.H., Yang, T.J., Rosenblum, M.K., Ballangrud, Å, Young, R.J., Zhang, Z., Beal, K., 2015. Long-term risk of radionecrosis and imaging changes after stereotactic radiosurgery for brain metastases. J. Neurooncol. 125, 149-156. https://doi.org/10.1007/s11060-0151881-3. PubMed PMID: 26307446; PubMed Central PMCID: PMC4726630.

Koiso, T., Yamamoto, M., Kawabe, T., Watanabe, S., Sato, Y., Higuchi, Y., Yamamoto, T., Matsumura, A., Kasuya, H., 2016. Follow-up results of brain metastasis patients undergoing repeat Gamma Knife radiosurgery. J. Neurosurg. 125 (Suppl. 1), 2-10 PubMed PMID: 27903177.

Kurtz, G., Zadeh, G., Gingras-Hill, G., Millar, Ba, Laperriere, Nj, Bernstein, M., Jiang, H., Ménard, C., Chung, C., 2014. Salvage radiosurgery for brain metastases: prognostic factors to consider in patient selection. Int. J. Radiat. Oncol. Biol. Phys. 88, 137-142. https://doi.org/10.1016/j.ijrobp.2013.10.003. PubMed PMID: 24331660.

Kuwahara, Y., Tomita, K., Urushihara, Y., Sato, T., Kurimasa, A., Fukumoto, M., 2018. Association between radiation-induced cell death and clinically relevant radioresistance. Histochem. Cell Biol. 150 (6), 649-659. https://doi.org/10.1007/s00418 018-1728-z. Epub 2018 Sep 20. Review. PubMed PMID: 30232589.

Kwon, K.Y., Kong, D.S., Lee, J.I., Nam, D.H., Park, K., Kim, J.H., 2007a. Outcome of repeated radiosurgery for recurrent metastatic brain tumors. Clin. Neurol. Neurosurg. 109, 132-137 PubMed PMID: 16930821.

Kwon, K.Y., Kong, D.S., Lee, J.I., Nam, D.H., Park, K., Kim, J.H., 2007b. Outcome of repeated radiosurgery for recurrent metastatic brain tumors. Clin. Neurol. Neurosurg. 109, 132-137 PubMed PMID: 16930821.

Lin, N.U., Lee, E.Q., Aoyama, H., Barani, I.J., Barboriak, D.P., Baumert, B.G., Bendszus, M., Brown, P.D., Camidge, D.R., Chang, S.M., Dancey, J., de Vries, E.G., Gaspar, L.E., Harris, G.J., Hodi, F.S., Kalkanis, S.N., Linskey, M.E., Macdonald, D.R., Margolin, K., Mehta, M.P., Schiff, D., Soffietti, R., Suh, J.H., van den Bent, M.J., Vogelbaum, M.A., Wen, P.Y., Response Assessment in Neuro-Oncology (RANO) group, 2015. Response assessment criteria for brain metastases: proposal from the RANO group. Lancet Oncol. 16, e270-8. https://doi.org/10.1016/S1470-2045(15)70057-4. PubMed PMID: 26065612.

Mahajan, A., Ahmed, S., McAleer, M.F., Weinberg, J.S., Li, J., Brown, P., Settle, S., Prabhu, S.S., Lang, F.F., Levine, N., McGovern, S., Sulman, E., McCutcheon, I.E., Azeem, S., Cahill, D., Tatsui, C., Heimberger, A.B., Ferguson, S., Ghia, A., Demonte, F., Raza, S., Guha-Thakurta, N., Yang, J., Sawaya, R., Hess, K.R., Rao, G., 2017. Postoperative stereotactic radiosurgery versus observation for completely resected brain metastases: a single-centre, randomised, controlled, phase 3 trial. Lancet Oncol. 18, 1040-1048. https://doi.org/10.1016/S1470-2045(17)30414-X. PubMed PMID: 28687375 .

Maranzano, E., Trippa, F., Casale, M., Costantini, S., Anselmo, P., Carletti, S., Principi, M., Caserta, C., Loreti, F., Giorgi, C., 2012. Reirradiation of brain metastases with radiosurgery. Radiother. Oncol. 102, 192-197. https://doi.org/10.1016/j.radonc. 2011.07.018. PubMed PMID: 21880387.

Maranzano, E., Terenzi, S., Anselmo, P., Casale, M., Arcidiacono, F., Loreti, F., Di Marzo, A., Draghini, L., Italiani, M., Trippa, F., 2019. A prospective phase II trial on reirradiation of brain metastases with radiosurgery. Clin. Transl. Radiat. Oncol. 17, 1-6. https://doi.org/10.1016/j.ctro.2019.04.003. PubMed PMID: 31061900; PubMed Central PMCID: PMC6487370.

McGrath, S., Zhao, X., Qin, Z.Z., Steele, R., Benedetti, A., 2019. One-sample aggregate data meta-analysis of medians. Stat. Med. 38, 969-984. https://doi.org/10.1002/sim. 8013.PubMed. PMID: 30460713.

McKay, W.H., McTyre, E.R., Okoukoni, C., Alphonse-Sullivan, N.K., Ruiz, J., Munley, M.T., Qasem, S., Lo, H.W., Xing, F., Laxton, A.W., Tatter, S.B., Watabe, K., Chan, M.D., 2017. Repeat stereotactic radiosurgery as salvage therapy for locally recurrent brain metastases previously treated with radiosurgery. J. Neurosurg. 127, 148-156. https://doi.org/10.3171/2016.5.JNS153051. PubMed PMID: 27494815.

McTyre, E., Ayala-Peacock, D., Contessa, J., Corso, C., Chiang, V., Chung, C., Fiveash, J., Ahluwalia, M., Kotecha, R., Chao, S., Attia, A., Henson, A., Hepel, J., Braunstein, S., 
Chan, M., 2018. Multi-institutional competing risks analysis of distant brain failure and salvage patterns after upfront radiosurgery without whole brain radiotherapy for brain metastasis. Ann. Oncol. 29, 497-503. https://doi.org/10.1093/annonc/ mdx740. PubMed PMID: 29161348.

Miller, J.A., Bennett, E.E., Xiao, R., Kotecha, R., Chao, S.T., Vogelbaum, M.A., Barnett, G.H., Angelov, L., Murphy, E.S., Yu, J.S., Ahluwalia, M.S., Suh, J.H., Mohammadi, A.M., 2016. Association between radiation necrosis and tumor biology after stereotactic radiosurgery for brain metastasis. Int. J. Radiat. Oncol. Biol. Phys. 96, 1060-1069. https://doi.org/10.1016/j.ijrobp.2016.08.039. PubMed PMID: 27742540 .

Minniti, G., Esposito, V., Clarke, E., Scaringi, C., Bozzao, A., Lanzetta, G., De Sanctis, V., Valeriani, M., Osti, M., Enrici, R.M., 2013. Stereotactic radiosurgery in elderly patients with brain metastases. J. Neurooncol. 111, 319-325. https://doi.org/10.1007/ s11060-012-1016-z. PubMed PMID: 23187817.

Minniti, G., Scaringi, C., Paolini, S., Clarke, E., Cicone, F., Esposito, V., Romano, A., Osti, M., Enrici, R.M., 2016. Repeated stereotactic radiosurgery for patients with progressive brain metastases. J. Neurooncol. 126, 91-97. https://doi.org/10.1007/ s11060-015-1937-4. PubMed PMID: 26369769.

Monaco 3rd, E.A., Bhatnagar, J.P., Xu, Y., Arai, Y., Niranjan, A., Huq, M.S., Lunsford, L.D., 2014. Evaluation of tumor progression and detection of new tumors during repeat Gamma Knife $^{\circledast}$ stereotactic radiosurgery utilizing the co-registration tool in Leksel Gamma Plan ${ }^{\oplus}$ : technical note. Stereotact. Funct. Neurosurg. 92, 300-305. https:// doi.org/10.1159/000365227. PubMed PMID: 25247389.

Moreau, J., Khalil, T., Dupic, G., Chautard, E., Lemaire, J.J., Magnier, F., Dedieu, V., Lapeyre, M., Verrelle, P., Biau, J., 2018. Second course of stereotactic radiosurgery for locally recurrent brain metastases: safety and efficacy. PLoS One 13 (4), e195608. https://doi.org/10.1371/journal.pone.0195608. PubMed PMID: 29621341; PubMed Central PMCID: PMC5886580.

Narloch, J.L., Farber, S.H., Sammons, S., McSherry, F., Herndon, J.E., Hoang, J.K., Yin, F.F., Sampson, J.H., Fecci, P.E., Blackwell, K.L., Kirkpatrick, J.P., Kim, G.J., 2017. Biopsy of enlarging lesions after stereotactic radiosurgery for brain metastases frequently reveals radiation necrosis. Neuro Oncol. 19, 1391-1397. https://doi.org/10. 1093/neuonc/nox090. PubMed PMID: 28472527; PubMed Central PMCID: PMC5596170.

Nieder, C., Spanne, O., Mehta, M.P., Grosu, A.L., Geinitz, H., 2011. Presentation, patterns of care, and survival in patients with brain metastases: what has changed in the last 20 years? Cancer 117, 2505-2512. https://doi.org/10.1002/cncr.25707. PubMed PMID: 24048799.

Noël, G., Proudhom, M.A., Valery, C.A., Cornu, P., Boisserie, G., Hasboun, D., Simon, J.M., Feuvret, L., Duffau, H., Tep, B., Delattre, J.Y., Marsault, C., Philippon, J., Fohanno, D., Baillet, F., Mazeron, J.J., 2001. Radiosurgery for re-irradiation of brain metastasis: results in 54 patients. Radiother. Oncol. 60, 61-67 PubMed PMID: 11410305.

Rades, D., Pluemer, A., Veninga, T., Hanssens, P., Dunst, J., Schild, S.E., 2007. Wholebrain radiotherapy versus stereotactic radiosurgery for patients in recursive partitioning analysis classes 1 and 2 with 1 to 3 brain metastases. Cancer 110, 2285-2292 PubMed PMID: 17922523.

Rae, A., Gorovets, D., Rava, P., Ebner, D., Cielo, D., Kinsella, T.J., DiPetrillo, T.A., Hepel, J.T., 2016. Management approach for recurrent brain metastases following upfront radiosurgery may affect risk of subsequent radiation necrosis. Adv. Radiat. Oncol. 1, 294-299. https://doi.org/10.1016/j.adro.2016.08.007. PubMed PMID: 28740900; PubMed Central PMCID: PMC5514163.

Rana, N., Pendyala, P., Cleary, R.K., Luo, G., Zhao, Z., Chambless, L.B., Cmelak, A.J., Attia, A., Stavas, M.J., 2017. Long-term outcomes after salvage stereotactic radiosurgery (SRS) following in-field failure of initial SRS for brain metastases. Front. Oncol. 7, 279. https://doi.org/10.3389/fonc.2017.00279. PubMed PMID: 29218301; PubMed Central PMCID: PMC5703829.

Schüttrumpf, L.H., Niyazi, M., Nachbichler, S.B., Manapov, F., Jansen, N., Siefert, A, Belka, C., 2014. Prognostic factors for survival and radiation necrosis after stereotactic radiosurgery alone or in combination with whole brain radiation therapy for 1 3 cerebral metastases. Radiat. Oncol. 9, 105. https://doi.org/10.1186/1748-717X-9105. PubMed PMID: 24885624; PubMed Central PMCID: PMC4036428.

Shaw, E., Scott, C., Souhami, L., Dinapoli, R., Kline, R., Loeffler, J., Farnan, N., 2000. Single dose radiosurgical treatment of recurrent previously irradiated primary brain tumors and brain metastases: final report of RTOG protocol 90-05. Int. J. Radiat. Oncol. Biol. Phys. 47, 291-298 PubMed PMID: 10802351.

Shen, C.J., Rigamonti, D., Redmond, K.J., Kummerlowe, M.N., Lim, M., Kleinberg, L.R., 2016. The strategy of repeat stereotactic radiosurgery without whole brain radiation treatment for new brain metastases: outcomes and implications for follow-up monitoring. Pract. Radiat. Oncol. 6, 409-416. https://doi.org/10.1016/j.prro.2016.04. 004. PubMed PMID: 27687187.

Shultz, D.B., Modlin, L.A., Jayachandran, P., Von Eyben, R., Gibbs, I.C., Choi, C.Y.H., Chang, S.D., Harsh 4th, G.R., Li, G., Adler, J.R., Hancock, S.L., Soltys, S.G., 2015. Repeat courses of stereotactic radiosurgery (SRS), deferring whole-brain irradiation, for new brain metastases after initial SRS. Int. J. Radiat. Oncol. Biol. Phys. 92 (5),
993-999. https://doi.org/10.1016/j.ijrobp.2015.04.036. PubMed PMID: 26194677.

Shuto, T., Fujino, H., Inomori, S., Nagano, H., 2004. Repeated gamma knife radiosurgery for multiple metastatic brain tumours. Acta Neurochir. (Wien) 146 (9), 989-993 discussion 993. PubMed PMID: 15340810.

Sneed, P.K., Mendez, J., Vemer-van den Hoek, J.G., Seymour, Z.A., Ma, L., Molinaro, A.M., Fogh, S.E., Nakamura, J.L., McDermott, M.W., 2015. Adverse radiation effect after stereotactic radiosurgery for brain metastases: incidence, time course, and risk factors. J. Neurosurg. 123, 373-386. https://doi.org/10.3171/2014.10.JNS141610. PubMed PMID: 25978710.

Sperduto, P.W., Kased, N., Roberge, D., Xu, Z., Shanley, R., Luo, X., Sneed, P.K., Chao, S.T., Weil, R.J., Suh, J., Bhatt, A., Jensen, A.W., Brown, P.D., Shih, H.A., Kirkpatrick, J., Gaspar, L.E., Fiveash, J.B., Chiang, V., Knisely, J.P., Sperduto, C.M., Lin, N., Mehta, M., 2012. Summary report on the graded prognostic assessment: an accurate and facile diagnosis-specific tool to estimate survival for patients with brain metastases. J. Clin. Oncol. 30 (4), 419-425. https://doi.org/10.1200/JCO.2011.38.0527. PubMed PMID: 22203767; PubMed Central PMCID: PMC3269967.

Stafinski, T., Jhangri, G.S., Yan, E., Menon, D., 2006. Effectiveness of stereotactic radiosurgery alone or in combination with whole brain radiotherapy compared to conventional surgery and/or whole brain radiotherapy for the treatment of one or more brain metastases: a systematic review and meta-analysis. Cancer Treat. Rev. 32, 203-213 PubMed PMID: 16472924.

Sterne, J.A., Hernán, M.A., Reeves, B.C., Savović, J., Berkman, N.D., Viswanathan, M., Henry, D., Altman, D.G., Ansari, M.T., Boutron, I., Carpenter, J.R., Chan, A.W. Churchill, R., Deeks, J.J., Hróbjartsson, A., Kirkham, J., Jüni, P., Loke, Y.K., Pigott, T.D., Ramsay, C.R., Regidor, D., Rothstein, H.R., Sandhu, L., Santaguida, P.L., Schünemann, H.J., Shea, B., Shrier, I., Tugwell, P., Turner, L., Valentine, J.C., Waddington, H., Waters, E., Wells, G.A., Whiting, P.F., Higgins, J.P., 2016. ROBINS-I: a tool for assessing risk of bias in non-randomised studies of interventions. BMJ 355, i4919. https://doi.org/10.1136/bmj.i4919. PubMed PMID: 27733354; PubMed Central PMCID: PMC5062054.

Stumpf, P.K., Cittelly, D.M., Robin, T.P., Carlson, J.A., Stuhr, K.A., Contreras-Zarate, M.J., Lai, S., Ormond, D.R., Rusthoven, C.G., Gaspar, L.E., Rabinovitch, R., Kavanagh, B.D., Liu, A., Diamond, J.R., Kabos, P., Fisher, C.M., 2019. Combination of Trastuzumab Emtansine and stereotactic radiosurgery results in high rates of clinically significant radionecrosis and dysregulation of Aquaporin-4. Clin. Cancer Res. 25, 3946-3953. https://doi.org/10.1158/1078-0432.CCR-18-2851. PubMed PMID: 30940654 PubMed Central PMCID: PMC6751332.

Szeifert, G.T., Atteberry, D.S., Kondziolka, D., Levivier, M., Lunsford, L.D., 2006. Cerebral metastases pathology after radiosurgery: a multicenter study. Cancer 106, 2672-2681 PubMed PMID: 16700040.

Telera, S., Fabi, A., Pace, A., Vidiri, A., Anelli, V., Carapella, C.M., Marucci, L., Crispo, F., Sperduti, I., Pompili, A., 2013. Radionecrosis induced by stereotactic radiosurgery of brain metastases: results of surgery and outcome of disease. J. Neurooncol. 113, 313-325. https://doi.org/10.1007/s11060-013-1120-8. PubMed PMID: 23525948.

Terakedis, B.E., Jensen, R.L., Boucher, K., Shrieve, D.C., 2014. Tumor control and incidence of radiation necrosis after reirradiation with stereotactic radiosurgery for brain metastases. J. Radiosurg. SBRT 3, 21-28 PubMed PMID: 29296381; PubMed Central PMCID: PMC5725326.

Truong, M.T., St Clair, E.G., Donahue, B.R., Rush, S.C., Miller, D.C., Formenti, S.C., Knopp, E.A., Han, K., Golfinos, J.G., 2006. Results of surgical resection for progression of brain metastases previously treated by gamma knife radiosurgery. Neurosurgery 59, 86-97 discussion 86-97. PubMed PMID: 16823304.

Tsuruda, J.S., Kortman, K.E., Bradley, W.G., Wheeler, D.C., Van Dalsem, W., Bradley, T.P., 1987. Radiation effects on cerebral white matter: MR evaluation. AJR Am. J. Roentgenol. 149, 165-171 PubMed PMID: 3495977.

Vecil, G.G., Suki, D., Maldaun, M.V., Lang, F.F., Sawaya, R., 2005. Resection of brain metastases previously treated with stereotactic radiosurgery. J. Neurosurg. 102, 209-215 PubMed PMID: 15739546.

Vellayappan, B., Tan, C.L., Yong, C., Khor, L.K., Koh, W.Y., Yeo, T.T., Detsky, J., Lo, S., Sahgal, A., 2018. Diagnosis and management of radiation necrosis in patients with brain metastases. Front. Oncol. 8, 395. https://doi.org/10.3389/fonc.2018.00395. PubMed PMID: 30324090; PubMed Central PMCID: PMC6172328.

Venur, V.A., Ahluwalia, M.S., 2016. Targeted Therapy in Brain Metastases: Ready for Primetime? Am. Soc. Clin. Oncol. Educ. Book 35, e123-30. https://doi.org/10. 14694/EDBK 100006. PubMed PMID: 27249714.

Wowra, B., Siebels, M., Muacevic, A., Kreth, F.W., Mack, A., Hofstetter, A., 2002 Repeated gamma knife surgery for multiple brain metastases from renal cell carcinoma. J. Neurosurg. 97, 785-793 PubMed PMID: 12405364.

Yomo, S., Hayashi, M., 2016. Salvage stereotactic radiosurgery with adjuvant use of bevacizumab for heavily treated recurrent brain metastases: a preliminary report. J. Neurooncol. 127, 119-126. https://doi.org/10.1007/s11060-015-2019-3. PubMed PMID: 26619997.

Yoshii, Y., 2008. Pathological review of late cerebral radionecrosis. Brain Tumor Pathol. 25, 51-58. https://doi.org/10.1007/s10014-008-0233-9. PubMed PMID: 18987829. 